1

2

3

4

5

6

7

8

9

10

11

12

13

14

12

3

14

Coaching and Coach Development in New Zealand

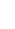

5

Lynn Kidman

AUT University, SPRINZ

New Zealand

Dave Keelty

Greater Auckland Coaching Unit - Auckland Sport

New Zealand 
Abstract

16 For a small country with a population of 4.47 million (Statistics New Zealand, 2015), New

17 Zealand achieves great success on the world sporting stage. One of the many contributors to

18 this success is New Zealand's commitment to developing coaches with an emphasis on

19 continuous improvement through the provision of ongoing learning opportunities for coaches

20 (SPARC, 2006). To achieve this focus, and based on a Ministerial Taskforce findings that,

21 "Coaching is in urgent need of support and development" (Ministerial Taskforce, 2001, p.10)

22 Sport and Recreation New Zealand (SPARC) established a consultancy group to review and

23 redevelop coaching. The consultancy group was comprised of a "coaching team"” and "key

24 players in coaching"' (SPARC, 2004, p.5). An outcome of this consultation was the

25 production of the New Zealand Coaching Strategy (SPARC, 2004). Based on robust

26 discussion on many issues of how people learn and coaching development philosophies, the

27 Coach Development Framework (CDF) was established in 2006. Since its establishment, the

28 CDF has been guiding coach development in New Zealand, placing the responsibility for this

29 development on the National Sporting Organisations (NSOs).

30

31 KEY WORDS: coach development, athlete centred, ongoing learning 
New Zealand/Aotearoa (the land of the Long White Cloud) is an island country in the Pacific Ocean comprised of two islands North (Te Ika-a-Māui, $)$ and South (Te Waipounamu) and numerous small islands with a population of 4.47 million (Statistics New Zealand, 2015). Australia is its nearest neighbour. The five largest cities are Auckland (with one-third of the country's population), Christchurch (in the South Island), Wellington, Hamilton and Tauranga. New Zealand, as a Pacific nation, has a majority population with European (69\%), Maori (14.6\%) and Pasifika (6.9\%) people, as well as a multi-cultural mix of immigrants, with Asians (9.2\%) the highest (Statistics New Zealnad, 2015).

New Zealand legislative authority is a cabinet which is led by a Prime Minister and is organised into 11 regional councils and 67 territorial authorities for local government purposes. Sport in New Zealand reports to the Minister for Sports and Tourism, the guardian of sport in the country. Within Sport NZ, they oversee 92 National Sports Organisations (NSOs) and 17 Regional Sports Trusts (RSTs).

\section{Coaching and Coach Development in New Zealand}

Within Sport NZ sits a governing body that oversees coach development. As of 2015, two coaching managers in Sport NZ are dedicated to oversee this important endeavour. The NSOs receive funding for coach development from Sport NZ. Each NSO is responsible and autonomous in designing coach development strategic plans, including both community and high performance coaching. The responsibility of training coaches rests firmly with the NSOs and Sport NZ guides coaches in their strategic planning to meet the guidelines of the CDF.

There are also many regional sporting organisations (RSOs) who have a responsibility of delivering, designing and governing the NSO coach development opportunities for their local coaches. These RSOs respond to the needs of the schools and clubs in their regions, and work with regional sports trusts (RSTs) to organise these learning opportunities. The RSTs 
provide region-wide leadership, strategic direction and a single point of contact (including coaching) for stakeholders in their region. In addition to the government funded coaching organisations, there are tertiary coach education opportunities in the form of Bachelors, Masters and $\mathrm{PhD}$ degrees.

In 1977, based on a seminar to establish a direction for coaching in New Zealand, an agreement was made by the participants and the New Zealand Association of National Sports Coaches (NZANSC) to form a national coaching body (Kidman, Hadfield \& Chu, 2000). From 1980 to 1983, NZANSC met annually and created and developed the Coaching Association of New Zealand (CANZ). CANZ was recognised as a key coach education deliverer at the 'New Zealand Sport Through the 80's Conference' in 1984. In 1985, CANZ was identified as the key provider of coach education and a year later, CANZ level I was implemented nationally. In 1989, the then Hillary Commission's International Sport Priorities Board established that CANZ was a key service organisation for New Zealand coaches and sport.

Subsequently in 1991, CANZ was reconstituted as an incorporated business called Coaching New Zealand (CNZ). With the CNZ board as its governing body, the Hillary Commission continued to fund $\mathrm{CNZ}$ and mandated the business to develop a multi-level coach education standardised, accredited scheme. Until 1997, CNZ was the major coaching body representing coaches and provided and organised delivery of a coach education accredited scheme and opportunities for coach networking amongst coaches in New Zealand. CNZ was disestablished in 1997, and the Hillary Commission became the governing body for coach education. In the middle of 2000, a Ministerial Taskforce on Sport, Fitness and Leisure in New Zealand was established to "re-examine the structure of sport in New Zealand" (Sam, 2005, p. 212). The Graham report concluded in 2001 (Ministerial Taskforce, 2001), and indicated 
that the sport, fitness and leisure sectors were in 'crisis' (Sam, 2003; Sam \& Jackson, 2004).

One of the actions stemming from the Ministerial Taskforce was the restructuring of the sport, leisure and fitness sectors, resulting in the establishment of Sport and Recreation New Zealand (SPARC). Upon its establishment, SPARC used the Taskforce's findings that "Coaching is in urgent need of support and development" (Ministerial Taskforce, 2001, p.10) as its mandate for change. The focus on coaching emerged in the form of a consultancy group (selected by SPARC), which comprised a "coaching team" and "key players in coaching"” (SPARC, 2004, p.5). An outcome of this consultation was the production of the New Zealand Coaching Strategy (SPARC, 2004).

Included in the SPARC's coaching department in 2004, once the NZ Coaching Strategy was implemented, existed two dedicated teams, one who focused on High Performance Sport and another whose focus was community coaching. As a result of the focus on community coaching within the NZ Coaching Strategy, the Coaching Manager of SPARC, Paul Ackerley ${ }^{1}$ organised a task force (working party, see Figure 1) to determine the direction of coaching in New Zealand. The coach task force consisted of members from National Sport Organisations (NSOs), coach development officers, academics in coaching and sport psychology, and coaches. In an interview by Tania Cassidy to create an ethnodrama of the situation, (see Cassidy and Kidman, 2015), the first author of this paper was interviewed about this task force and the openness and acceptance of the diversity of thinking being practised:

...the fact that we had a clean slate, the fact that the education system is wrought with problems, according to everyone on the working party. We had coaches who were brilliant without accreditation and we had national coaches who hadn't been through

\footnotetext{
${ }^{1}$ We dedicate this article to Paul who passed away before he saw today's development in coaching. Much of what occurs within the current Coach Development Framework is due to Paul's dedicated work. Thank you Paul.
} 
the coach education system and were fantastic. The whole thing about the education system and the fact that you get a degree didn't mean you were a good coach. So therefore, Paul asked how could we develop coaches so that they were fantastic coaches and whether they have a qualification or not? That discussion was probably the essence of the problematic nature of the word education. If we keep calling it education, there is a connotation that there is an end point that coaches can get to and we don't want coaches to stop learning. We want them to value that they should keep developing for the betterment of athlete performance and human beings. It was a whole bunch of things. It probably started from being able to have a clean slate and being able to discuss openly. At some point we discussed well what is a coach.
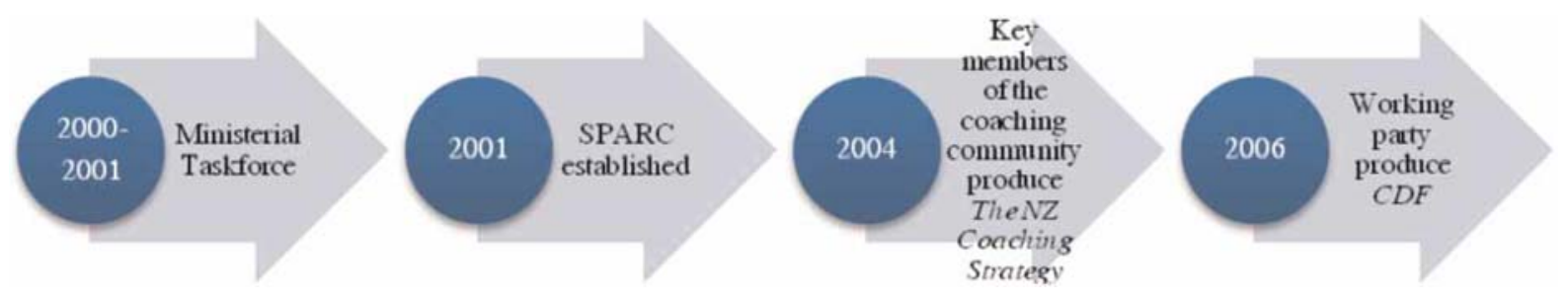

Figure 1. The relationship between the Ministerial Taskforce, SPARC, The New Zealand Coaching Strategy and the Coach Development Framework. (Cassidy \& Kidman 2010, p.310)

\section{The Coach Development Framework}

In development discussions, the members of the task force were in agreement (mostly based on coach experience) that previous orthodox coach education programmes in New Zealand had not worked. This is illustrated by the comment that, "in the first meeting there 
was a real consensus around this [the CDF] isn't education, it is about development" (L.

Johnston, personal communication, as cited in Cassidy \& Kidman, 2010, p.314). A common perception, as to why the previous coach education programmes had not worked, was "that many coaches negatively associated coach education with formal, classroom and theory orientated practices that focused on the 'what' (knowledge) in coaching and not the 'how' (skills) and "why' (understanding)" (p. 314). This sort of understanding occurred from coaches historically completing standardised, accredited courses where the learning was minimal (Cushion, Jones \& Armour, 2003). Thus, based on the influence of the task force, there was a shift of thinking that focused on continuous ongoing professional development, which valued formal and informal learning opportunities.

The outcome of this vision is illustrated in the CDF where it encourages coaches to view their learning and development as ongoing and continuous, as well as being athletecentred, whereby understanding the athletes and their learning is a major principle. As much research has suggested, the difficulty of coaches trying to apply what they learn in formal environments in coaching (Cushion, et al., 2003; Cushion, 2006), the task force mandated more application of knowledge to the context of individual coaching.

In 2006, the CDF was released to the National Sport Organisations (NSOxs) and SPARC emphasised that the sports would be responsible for creating their own coach development strategies. SPARC began to work with the sports to help develop a coaching development strategic plan with the guidance of the CDF.

In 2010, another restructure of the national sporting body occurred and SPARC was divided into two entities, both of which have coach development strategies, High Performance Sport New Zealand (HSPNZ) and Sport NZ. The CDF largely remains unchanged, but has been further clarified. In the current NZ Coaching Strategy (see Figure 2) there exists a Coach Development Plan whereby Sport NZ has provided a framework for each 
of four coaching communities (foundation, development, performance and high performance). The coaching communities are explained below:

\section{Foundation Coaching Community}

(Supporting participants in the Learn stage)

Foundation coaches support participants enjoying their first experiences in organised sport. The vast majority of the participants will be primary school aged children trying out a range of modified sports in either a club or primary school setting.

Development Coaching Community

(Supporting participants in the Participate stage)

Development coaches support a wider range of participants including the young people who continue in organised sport through the later years of primary school, the secondary school students in both the school and club setting and the adults who continue to play organised sport in a non-elite environment.

Performance Coaching Community

(Supporting athletes in the Perform Stage)

Performance coaches support that narrower range of athletes who have shown extra ability and have moved on to some sort of district or regional representative sport at either a youth or adult level.

High Performance Coaching Community

(Supporting athletes in the Excel Stage)

High Performance coaches support the athletes who have progressed to the top of their sport within New Zealand and are now competing on an international stage (Sport NZ, 2010, p. 6-7). 


\section{MEW ZAALAND GOAGHING STRATEGY}
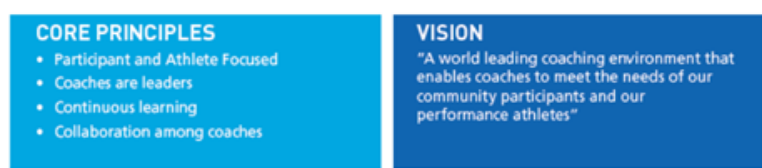

KEY OBJECTIVES

- Cosches at all livels are valued and supported

- Coaching communities are developed to meet

- A collaborative culture sustaining life long learning

Delivered through aligned Community Sport and High Performance Coaching Plans

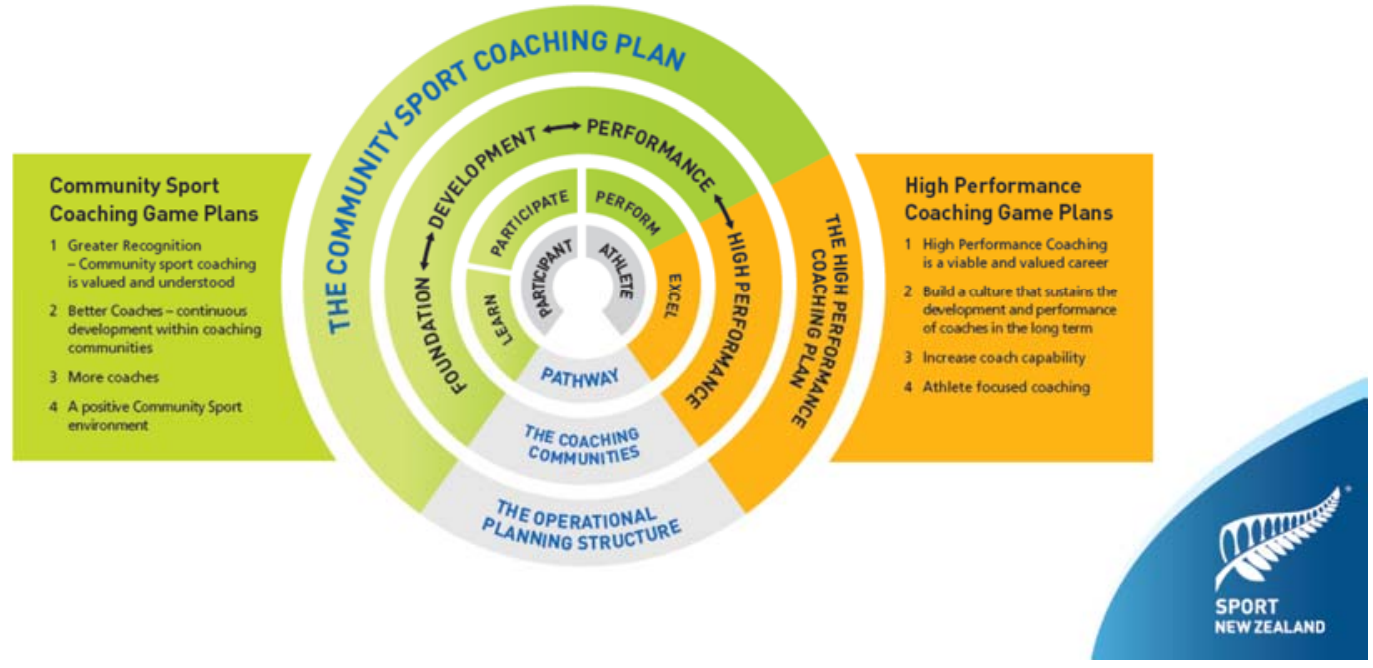

182 Figure 2.

New Zealand Coaching Strategy 2012-2020 (Sport NZ, 2012)

These communities serve as the backbone to coach development in New Zealand,

with a belief that coaches learn better in their context of understanding and practice. Based on

the communities, the following section provides some examples of coach development

implementation in New Zealand.

\section{Implementation}

National Sporting Organisations (NSOs) are the drivers of coach development in their

own sporting codes and create their own strategic frameworks, pathways and plans (for an

example, see http://www.nzfootball.co.nz/index.php?id=853). The NSOs fund Regional 
provide learning opportunities that meet the intentions of their strategic plans. Regional Sports Trusts (RSTs) play a key function in supporting NSOs and RSOs around capabilities and also provide facilitation on the generic skills of coaching. RSTs are predominantly funded by Sport NZ to fill this coach development role, among others.

In Auckland, four RSTs work to support the numerous NSOs and RSOs in New Zealand's most populous city. In 2008, the four RSTs in Auckland agreed to combine their coaching outcomes and funding from Sport NZ and formed the Greater Auckland Coaching Unit (GACU). GACU provides programmes, support and resources for coaches and for organisations committed to improving the quality of their coach development processes. GACU also plays an important leadership role in advocating for the development of coaches in Auckland. The GACU team is comprised of one director, four coaching advisors (one is based in each of four regions in Auckland) and one communications administrator. The four coaching advisors are a key link in creating alignment between the Sport NZ Community Coaching Plan (see Figure 2) and coaches who are at the 'coal face' and work with athletes. Their role is twofold: they are coach developers, running workshops/seminars for coaches, mentoring coaches and providing resource support for coaches and; are the key coach development contacts for the RSOs and NSOs in Auckland. These advisors also support sports clubs, secondary and primary schools.

David Keelty (second author), is based in the North of Auckland and works for the Greater Auckland Coaching Unit (GACU). The following three projects or programmes discussed are examples of the work that David is leading and/or supporting in his role at his Regional Sports Trust (RST) North Harbour. David works across three of the four coaching communities outlined in the Sport NZ Coaching Plan (foundation, development and performance coaching communities). The fourth coaching community example is presented subsequent to Dave's examples. 
219

220

221

222

223

224

225

226

227

228

229

230

231

232

233

234

235

236

237

238

239

240

241

242

\section{Foundation Community Example}

Through KiwiSport ${ }^{2}$ funding, NSOs, RSOs, clubs and schools can apply to RSTs for

funding to provide sporting and coach development opportunities to help young people (5-18 years old). To provide these opportunities, the GACU advisors monitor KiwiSport funded schools, specifically their coach development opportunities. One strategy used to support organisations around the quantity and quality of coaching for these projects is a GACUinitiated KiwiSport minimum coaching standard that all coaches must complete. The purpose of this project is to monitor the quality assurance for sport being delivered to young people.

The minimum standards include five actions that coaches who receive KiwiSport funding must achieve which actions include: attend a coach development workshop; complete an online safety module; sign a Code of Ethics; be observed coaching; and be police vetted.

Coach development workshop. All KiwiSport coaches must attend a workshop that covers important topics to help them understand how to work with young people. The topics covered are based on research by the advisors about best practice and is also based on feedback from previous coach development projects. The 'standardised' workshops are two hours in length, and are generic in content so coaches from a variety of sports can attend together in their foundation coaching community. The networking with other sports is seen as one of the strengths of the minimum standards process, as it allows for 'cross-pollination' of ideas among coaches of different sporting codes (Kidman \& Penney, 2014). Through the 5+ years of implementation, GACU has adapted the content and delivery of the workshop to continue a focus of ongoing learning. There are some consistent themes that continue in the workshop: time on task for participants; growth and development of young people and the implications this has on coaching; encouragement of teacher involvement in school-based sessions; and safety.

\footnotetext{
${ }^{2}$ Kiwi Sport is a New Zealand government funding initiative to support sport for school-aged children.
} 
Online safety module. For the foundation coaching community, coaches complete an

online safety module housed on the GACU website (see

https://www.gacu.co.nz/wizard.cfm?supplier=gacu\&module=safetynet). The online learning tool takes about 20-30 minutes to complete and covers aspects of safe practice that coaches need to consider, including physical and emotional safety of athletes and injury management. The tool is interactive, with different types of activities that focus on a safe environment. The resource also includes links to other websites to give coaches a chance to further expand their knowledge.

Code of ethics. In addition to this online safety module, KiwiSport-funded coaches must sign the Sport NZ Coaches' Code of Ethics, which outlines the expectations and behaviours that are appropriate for coaches, including:

1. Respect the rights, dignity and worth of every individual athlete as a human being;

2. Maintain high standards of integrity;

3. Be a positive role model for your sport and athletes and act in a way that projects a positive image of coaching;

4. Maintain professional responsibilities;

5. Make a commitment to providing a quality service to your athletes;

6. Provide a safe environment for training and competition; and

7. Protect your athletes from any form of personal abuse. (Sport NZ, 2015)

Coach observation. The RST, Harbour Sport (North of Auckland), has two coach advisors who observe KiwiSport coaches in action. This process of each observation involves:

Step 1: Observe $1^{\text {st }}$ session.

Step 2: Observe $2^{\text {nd }}$ session.

Step 3: Meet with coach to give feedback and discuss what was observed. 
Step 4: Observe $3^{\text {rd }}$ session.

Coaches observed will have several contexts to follow. For example, a coach may be working with seven year olds in session one, and then 12 year olds in session two. The advisor does not meet with these coaches until after the second session so they can increase the quality of feedback by gathering further information. The purpose of these observations is not to assess the coaches, but to provide feedback and encourage them to reflect on their coaching. The reflection aspect has an expectation that coaches will use this feedback in their next session and deliver a better quality learning environment. Two examples of written observations for two foundation community situations are provided below:

\section{$1^{\text {st }}$ Example:}

Two classes working together (around 52 children). Children were split in 2 groups to play softball with 28 kid as fielders and 24 as batters. This resulted in long waiting queues, with significant amounts of time between each involvement in the game. Children in the field very rarely involved. Equipment used was one bat and one ball, more equipment available on the side of the field not being utilised.

\section{Great questioning. Great environment, especially considering the challenges of the} weather and no hall. There were long queues (5-6 children), with more balls available. Coach needs more control of class, children a bit lively. There was a long time doing the same activity, and the children got noticeably bored. Great game, but too many children per team. More equipment could have been utilised to reduce the number and increase opportunities of practice. Teacher wasn't involved throughout the session so how can they continue the development when the coach isn't there.

$2^{\text {nd }}$ Example: 
There are two coaches for this team.

In terms of group management:

Both coaches showed good level of confidence delivering and good control of children's behaviours. Is good to see that two different coaches have a similar management style to manage/control children. Additionally children response in a well manner to this.

In terms of content:

Both coaches showed that they know what they are coaching and key points to teach. Some Fundamental Movement Skills were taught as part of the technical skills. Use of analogies to teach techniques/rules was useful and well received for children. In terms of class environment: The two coaches have the skills to create a fun, safe and participative environment during their sessions.

To improve:

"Teacher involvement" is an area that they should be improving in some way, is a Kiwisport goal and also an opportunity for sports to educate/up-skill teachers that shouldn't be missed. Please let me know if you need support in this area. I want to acknowledge that during this observation process, the two coaches showed highly professional attitude during delivery and keeping the communication open and clear. Additionally, due to their passion and commitment during their delivery the rapport created with children and teachers was great. As example, I received great comments and feedback from teachers about Touch Rugby's sessions and coaches.

Finally I would like to encourage them to keep using their expertise as coaches to change and/or adapt sessions or activities (if required) to meet children's needs and 
level of skills. Sessions plans are a guide that must be flexible and adaptable as every class/child is different.

Police vetting. Coaches are police vetted to ensure they are appropriate to work with young people. This service is offered by Harbour Sport (an RST) when the coaches' sport or club cannot perform the vetting directly with the New Zealand Police. The New Zealand Police check each coach's background. If the check comes back with an issue, that person is not allowed to coach.

The minimum standards process starts every school term, with the coach development workshop held in the first 1-2 weeks of the term, and the rest of the minimum standards requirements completed after this workshop. If any of the minimum standards are not achieved within that term, a follow up email is sent to both the coach and the organisation they represent to outline what is still required to coach in a KiwiSport project. If after another three weeks that still hasn't been achieved the coach is withdrawn from the project.

\section{Development Community Example}

In 2012, Harbour Sport in alignment with GACU, introduced the Coach Support Initiative (CSI) pilot project with a focus of improving the leadership, planning and alignment of coaching in secondary schools. The KiwiSport investment in CSI helps increase participation numbers and skill levels of secondary school students. By working top down with senior management to develop the school coaching culture and bottom up by directly supporting the coaches themselves, CSI coaching leaders contribute to coach development. Addressing coaching throughout the whole school, these leaders provide a variety of development opportunities, support and advocacy.

It is now widely acknowledged that coaches occupy a central and critical position in the athletic setting and sporting experience of athletes, with many possible 'spill-over' effects 
into other areas of athletes' lives (Jones, et al., 2003; Reinboth, Duda \& Ntoumanis, 2004;

Smoll \& Smith, 1981). GACU believes there is a direct relationship between improving the quality of coaching, and improving the level of participation in sport of young people. The CSI project has a number of core principles which are based on New Zealand's Coach Development Plan, which include:

1. Quality coaches are key enablers of participation in sport. Recent research out of the United Kingdom studied the impact coaching has on participants (Hopkinson, 2014). A key finding from their research was "significant proportions (between $66 \%$ and $72 \%$ ) of young people say being coached has increased their enjoyment, passion and commitment to sport, as well as the time they spend playing" (p. 18). To take that a step further, the research also highlights a link between the quality of coaching and young people's enjoyment of playing sport.

2. Coaches who feel valued and supported in their roles are more likely to continue to coach. Across schools in New Zealand, the majority of coaches are volunteers so SPARC's research (2008) offers sound advice for organisations working with volunteers. Key findings from their research suggest quality volunteer management needs organisations to:

- take into consideration the amount of time volunteers give up and recognise this;

- provide expectations and roles/responsibilities to all volunteers;

- develop family-centric strategies and systems to retain volunteers; and

- communicate regularly with volunteers.

If an organisation only focuses on its own interests, and does nothing to support and value its volunteers it is at risk of losing them. 
3. Strong advocacy and leadership is critical to the success of coach development in schools. This belief is supported by SPARC's volunteer research (2008), which indicated volunteers prefer being part of an organisation that has strong leadership. Without strong leadership volunteers may be uninspired and unsure about what is expected of them and may eventually lack commitment, which will see them disengage. Organisations should have a dedicated leader to support coaches; someone who is passionate about the positive impact coaching can have on their school. Sport NZ's evidence highlighted where there is strong coaching leadership there also exists strong coaching communities (SPARC, 2008)

Each participating school in the CSI project receives funding to employ a Coaching Leader, whose role is to provide strong leadership and advocacy for coaching. They effectively become the hub of coaching in their respective school by writing and implementing a coach management plan. Each of the school's coach leader is supported by a project leader in the school who provides guidance of best practice and facilitates the capability development of the school coaching leaders via workshops, networking and individual mentoring.

Results of implementation of CSI. A quantitative evaluation of the CSI initiative (2012-2013) was completed by Harbour Sport and the CSI group to determine the success of the CSI project within schools. Interestingly, The CSI project has increased participation of students/athletes from 4,535 in 2013 to 6,813 in 2014 . The number of coaches developed through this programme has also increased two fold (from 389 to 699).

Other qualitative evaluation suggests further successes in the CSI project, namely: 1. Five schools have implemented new coaching culture policies, designed to improve the experience of the athletes at these schools. 
2. Links have been developed among these schools and other sporting organisations e.g. RSOs, NSOs, professional sports franchises, primary schools, intermediate schools and tertiary education providers. These links have developed for a variety of reasons, ranging from coach recruitment, development and shared resources.

3. There has been a steady increase of uptake by Auckland schools, where 24 people are now working in the coach development space in Auckland. This number is a significant investment into coach development as a result of growing the reach of GACU out into the Auckland coaching community. The success of the Harbour Sport pilot influenced the implementation of a second CSI project based in the Waitakere (West of Auckland) region. Nine secondary schools invested in the West Auckland project. In 2014, there were 14 secondary schools participating in the project.

Issues regarding implementation. Engaging adult coaches and employing the coaching leaders have been two issues in the implementation of the CSI. The biggest challenge faced for each school involved is engaging adult coaches in development opportunities. Predominantly, there are two reasons cited in the evaluation of the CSI programme: 1) there is a prevailing attitude within the schools that "we can't ask too much of our coaches, as they are already giving up their time to coach". With this attitude, coaching leaders sometimes choose to hold back development opportunities to ensure their coaches don't feel overburdened and; 2) adult coaches are choosing not to attend development opportunities. The lack of attendance was not determined by the evaluation, but based on the advisors' experiences, have been noted as a lack of time and too many work commitments, family commitments, don't see the value in attending, are anxious or are worried about 
attending. The challenge of addressing these two reasons are being reflected upon going forward in 2015.

The second major issue is the Coaching Leader position is a part time role (depending on the school). The most number of hours a Coaching Leader is employed at a school is 20 hours with the least number of hours being six per week. Consequently, the roles are rather transient, with the people filling these roles often using them as a stepping stone into more full time employment in the sporting industry. Another significant challenge for the project is keeping quality people in the coaching leader roles so the impact is sustainable. As stated above, a fundamental principle of the CSI project is where there is strong coaching leadership there also exists strong coaching communities. For there to be strong coaching leadership there needs to be a leader who has built relationships with key people, a leader who has built trust, and who has gained respect from the coaches within their school.

\section{Performance Community Example}

In 2013, GACU piloted a coach development programme targeting coaches in the performance community called the Coach Advance Pilot Programme (CAPP). This programme is a 12 month programme that involved four all day workshops, each with a guest presenter and specific topic to cover in a workshop/seminar environment. The application process included coaches submitting a five minute video answering a few questions about themselves as coaches. Initially there was no limit to the number of coaches who could be part of the programme as this was the first time in Auckland a generic coach development programme was targeted for the performance coaching community. Initially, the intention was to test how many coaches would actually apply.

Eight coaches applied, with seven invited onto the programme. Two coaches were from netball, two from rugby union, and one each from cricket, triathlon and basketball. In addition to the four all day workshops throughout 2013, coaches completed video reflections 
on their application of the workshop learnings into their own coaching environments. At the final workshop, coaches evaluated the programme. A typical example from one of the coaches highlights the impact of the programme for him:

I just wanted to say thanks to everyone who has been involved with the programme this year. To Andy and the amazing team of ring ins, you were all sensational. You never struggled to generate new ways of thinking in us all, take us out of our comfort zone and get us all to challenge our and others ways of thinking and doing. (interview, rugby coach)

The success of the CAPP sparked Sport NZ's interest and led them to invest in a national programme, called Performance Coach Advance (PCA). This programme was rolled out nationally in 2014, with 24 coaches in Auckland, 18 coaches in Wellington and Canterbury, and 12 coaches in Waikato and the Bay of Plenty. The application process was adapted and modified where coaches were to be nominated by their NSO, before submitting a letter outlining why they wanted to be involved in the PCA programme. The underlying philosophy of this national programme is one of action learning (Revans, 1982). The programme is designed to follow a cyclical process, moving from act - reflect conceptualize - apply process. PCA aims to introduce coaches to this process and to encourage them to value ongoing learning.

Added to the four day workshops are four forums where the coaches meet to discuss learning from the workshops. After research on a similar high performance coach programme in New Zealand (see Kidman \& Penney, 2014), an emphasis on Communities of Practice $(\mathrm{CoP})$ networking is practised. The intention of the 'community of practice' is to enable coaches to lead and control the discussion and content within their particular coaching communities. 
Each coach in the programme also chooses someone from a list of support staff

465

466

467

468

469

470

471

472

473

474

475

476

477

478

479

480

481

482

483

484

485

486

created by the programme leader, whose role is to guide and support the coaches through the development programme. The coaches meet with their support staff member every month or so, using the coach's reflective journal as basis of their discussion. The support staff member also observes the coach in action in both training and event situations, consistent with an action learning philosophy (Revans, 1982).

\section{High Performance Community Example}

The fourth Sport NZ coaching community is the high performance sport coaching community which sits in a separate organisation called High Performance Sport New Zealand (HPSNZ). HSPNZ has a focus on coach development through their designated coaching community. HSPNZ's coaching strategic plan aligns with the New Zealand's Coach Development Plan (see Figure 2).

The Coach Accelerator Programme (CAP) (see http://hpsnz.org.nz/coaches/coachaccelerator-programme) is a principal coach development programme that sits within HPSNZ and is designed to enhance and accelerate coaches' learning, aligning to the CDF as having a long-term, ongoing development orientation. The CAP was established in 2009 with the stated objective "to create New Zealand coaches capable of producing World, Olympic and Paralympic champions within five years" (SPARC, 2010). Coaches working at the high performance level, as defined by the National Sports Organisations (NSOs) apply for a place on the programme and require nomination and endorsement from their respective NSO.

Selection involves a rigorous process, whereby coaches are nominated by their NSO, apply in writing $^{3}$ and are short-listed. Short-listed applicants participate in an interview that involves a series of realistic role simulations (coaching, partnering interactions, decision challenges and

\footnotetext{
${ }^{3}$ submitting a CV, nomination form and a technical programme
} 
judgements) designed to reflect issues and situations typically experienced by a Head Coach. The applicants then receive feedback about the application process.

Kidman and Penney (2014) undertook a research project to evaluate the pedagogical strategies of coaches participating in the CAP. Drawing on data from interviews with coaches, the programme manager and support staff, and from participant observations, it was found a major contributor to the success of the programme was coaches as learners within a community of practice. The strength of the CAP as a programme that was intended to facilitate and support the ongoing professional development and learning of coaches, and lies in the community and culture that has been established to date. The subtleties and complexities associated with the learning relations and networks developed and emerging in the context of the CAP was reported, but it is important to highlight "that amidst an externally initiated and resourced programme, the community of coaches and support staff have developed an internal dynamic that has been key to extending learning amongst the members" (p. 27). From the findings, it was evident that "trust and shared values and individual coaches' belief in the capacity of the programme and community to assist in advancing their coaching" (p. 27) enabled coaches to value the learning opportunities provided in the CAP.

Some of the main challenges that coaches identified during the research were administrative and organisational in nature. One such issue was relevance and meaning to broader sport organisations and the ability to sustain such a programme with ongoing structural changes that often impact on high performance sport.

\section{Coach Development Centre}

One other initiative that has been implemented into New Zealand coaching is the Auckland based Coach Development Centre (CDC). The CDC has an aim to enable coaches to have a place they can call their own, one where coaches can share ideas, develop and 
512 discuss all aspects of coaching and connect with like-minded people. With the coaching

513 mission of Sport NZ "to inspire and enable coaches to provide athletes with the coaching they

514 need" (SPARC, 2004), the CDC is one way to provide the opportunity to meet this mission.

515 The CDC practises the philosophy of the CDF and provides a place where coaches can pursue

516 the ongoing learning through a multifocus, multisport environment enabling cross fertilisation

517 of ideas and growth in expertise. Critically, it makes sense to have coaches develop alongside

518 cutting edge knowledge so they can contextualise and reap benefits from that knowledge with

519 immediate effect. In turn, better developed coaches should be able to deliver more capable

520 athletes with greater consistency. The CDC is a partnership with GACU and AUT University

521 where they provide a dedicated network of organisations and people supporting the

522 advancement of coach development and engaging in a thorough implementation of the holistic

523 approach to coaching.

Summary

New Zealand coach development focuses on athlete-centred coaching, with an emphasis for ongoing professional development and learning. This emphasis on coach learning and development (formally and informally) has shifted from an international trend of coaches gaining qualifications to one where the onus falls onto NSOs, rather than a centralised body. Coaching in New Zealand was able to develop due to the nature of an important Task Force that shifted from the notion of education to development. Much of what is occurring in New Zealand follows the research on coach learning, where there has been

532 shown to be limited learning through formal educational opportunities. The ongoing challenge is evident for providing athlete centred, coach led professional development opportunities. However, Sport NZ, HPSNZ and GACU will continue to develop learning opportunities with the CDF philosophical framework in mind. New Zealand coach 
536 development strives for the link that Hopkinson (2014) suggests between the quality of 537 coaching and young people's enjoyment of playing sport.

538

539 
541 Cassidy, T., \& Kidman, L. (2010) Initiating a national coaching curriculum: A paradigmatic shift? Physical Education and Sport Pedagogy, 15(3), 307-322.

Cassidy, T. and Kidman, L. (2015). Insights into the process of creating a coach development programme: The opportunities and challenges of ethnodrama. Qualitative Research in Sport, Exercise and Health, DOI: 10.1080/2159676X.2015.1012545

Cushion, C. (2006). Mentoring: Harnessing the power of experience. In R.L. Jones (Ed.). The Sports coach as educator: Re-conceptualising sports coaching, (pp. 128-144). Routledge: London.

Cushion, C. J., Armour, K. M., \& Jones, R.L. (2003) Coach education and continuing professional development: Experience and learning to coach, Quest, 55, 215-230.

Hopkinson, M. (2014). The impact of coaching on participants. Leeds, UK: The National Coaching Foundation.

Jones, R.L. (Ed) (2006). The sports coach as educator: Re-conceptualising sports coaching. London: Routledge.

Kidman, L., Hadfield, D., \& Chu, M (2000). The coach and the sporting experience. In C. Collins (ed), Sport in New Zealand society (pp 273-286). Palmerston North, NZ: Dunmore.

Kidman, L., \& Penney, D. (2014). Promoting and supporting coaches’ professional learning: Developing a community of practice. Journal of Athlete-centred Coaching, 1(1), 6-31.

Ministerial Taskforce. (2001). Getting set for an active nation: Report of the sport, fitness and leisure Ministerial taskforce. Wellington: The Taskforce.

Reinboth, M., Duda, J. L., \& Ntoumanis, N. (2004). Dimensions of coaching behavior, need 
satisfaction, and the psychological and physical welfare of young athletes. Motivation and Emotion, 28(3), 297-313.

Revans, R.W. (1982). What is action learning? Journal of Management Development, 1(3), 64-75.

Sam, M. P. (2005). The makers of sport policy: A task (force) to be reckoned with. Sociology of Sport Journal 21, 78-99.

Sam, M. P., \& Jackson, S. J. (2004). Sport policy development in New Zealand: Paradoxes of an integrative paradigm. International Review for the Sociology of Sport, 39(2), 20522.

Smoll, F. L., \& Smith, R. E. (1993). Enhancement of children's self-esteem through social support training for youth sport coaches. Journal of Applied Psychology, 78(4), 602610.

SPARC (2004). The New Zealand coaching strategy. Wellington, NZ: Astra Print.

SPARC (2006). Coach development framework. Wellington, NZ: Astra Print.

SPARC (2008a). Volunteers: the heart of sport. The experiences and motivations of sports volunteers. Wellington, NZ: Sport New Zealand.

SPARC (2008b). Review of the national coaching strategy's implementation. Wellington, NZ:

Sport and Recreation.

Sport NZ (2010). New Zealand coaching community coaching plan 2012-2020. Retrieved from http://www.sportnz.org.nz/assets/Uploads/attachments/managingsport/coaching/New-Zealand-Community-Sport-Coaching-Plan-20122020.pdf Sport NZ. (2012). New Zealand coaching strategy. Retrieved from 
http://www.sportnz.org.nz/Documents/coaching/The\%20New\%20Zealand\%20Coachi

589 ng\%20Strategy.pdf

590 Sport NZ. (2015, Jan 27). Coach's code of ethics. Retrieved from

$591 \quad$ http://www.sportnz.org.nz/assets/Uploads/attachments/managing-

$592 \quad$ sport/coaching/Coaches-Code-of-Ethics.pdf

593 Statistics New Zealand. (2015). Population clock. Retrieved from

$594 \quad$ https://www.google.com.au/webhp?sourceid=chrome-

595 instant\&ion $=1 \&$ espv $=2 \&$ ie $=U T F-8 \# q=$ population $\% 20$ of $\% 20$ new $\% 20$ zealand 596 